REVISTA DE DERECHO UNED, NÚM. 12, 2013

\title{
TRADICIÓN ROMANÍSTICA MEDIEVAL EN LOS PRINCIPIOS CONTRACTUALES VISIGÓTICOS
}

\author{
ROMANISTIC TRADITION MEDIEVAL IN CONTRACTUAL \\ PRINCIPLES VISIGOTH \\ MANUEl GaRCÍA GARRIDO \\ UNED
}

Resumen: La investigación localiza el antecedente de la tradición romanista medieval en materia de contratos en los principios contractuales visigóticos a pesar de que éstos optan por seguir los criterios de la jurisprudencia republicana frente a las reglas establecidas en el derecho clásico que, en España, es recuperado gracias a las Partidas de Alfonso X. Con ello se inicia una tradición romanística propia en la interpretación del principio de buena apreciable aún hoy en las sentencias más recientes del Tribunal Supremo.

Abstract: This research locates the antecedent of the medieval Roman tradition on contracts in Visigothic contractual principles even though they choose to follow the criteria of the republican jurisprudence against the rules in classical law that in Spain is recovered thanks to the Partidas of Alfonso X. This starts a self romanistic tradition in interpreting the good faith principle still noticeable in more recent judgments of the Spanish Supreme Court.

Palabras clave: Principios contractuales. Reglas. Las Partidas. Código de Eurico. Tradición romanística. Compraventa. Permuta. Comodato. Hurto.

Keywords: Contractual principles. Legal Rules. Partidas. Eurico Code. Roman tradition. Trading. Trade-in. Bailment. Theft.

Recepción original: 04/06/2013

Aceptación original: 06/06/2013 
Sumario: I. Introducción. II. Los principios sobre los contratos en la legislación de los visigodos. III. Titulus XXVII del Código de Eurico: De Commendatis vel Commodatis. IV. Titulus de venditionibus. V. Las Partidas. VI. Los códigos: A) Códigos americanos que reciben la tradición romanística de las Partidas. B) Códigos actuales. VII. La Jurisprudencia.

\section{INTRODUCCIÓN}

En los estudios sobre la cita e interpretación de las reglas y principios romanos de los Tribunales y Cámaras europeas he descubierto que vienen atribuidos, en la generalidad de los supuestos, a las instituciones y jurisprudencia romana cuando existen excepciones en las citas de principios de las legislaciones y doctrinas de los juristas medievales ${ }^{1}$.

De otra parte, la historia de las reglas romanas y sus modificaciones, y también su aplicación a las cambiantes circunstancias históricas, deben ser estudiadas en las etapas posteriores a Roma porque no solo son parte de la tradición romanística en Occidente y permanecen en muchas legislaciones, sino también constituyen principios jurídicos precedentes en la interpretación y aplicación de las decisiones jurisprudenciales actuales. Podemos utilizarlas también para encontrar los arcaísmos y vulgarizaciones de las instituciones clásicas. Trataré de los principios del derecho de los contratos en la legislación de los visigodos y en la recepción hispana del Derecho Romano.

1 Me refiero a mis siguientes publicaciones realizadas todas ellas el marco del Proyecto de Investigación fundamental no orientada, del Plan Nacional I+D+i, con referencia DER2010-19341, bajo el título «Antecedentes históricos de los principios generales del derecho y de la Unión Europea», financiado por el Ministerio de Economía y competitividad: I principi generali della tradizione giuridica nell'Unione Europea, en Convegno Iternazionale Aristec: Scienza giuridica, interpretazione e sviluppo del diritto europeo, 9 al 11 de Junio del 2011 (Atti del Convegno 2011); I principi del diritto europeo dei contratti (Commissione Lando), precedenti romani e risarcimento del damnno nell'esecuzione, en Convegno Praga-Moscu, Diritto Romano e legislazione europea, Convegno di Moscú 7 al 10 de Octubre de 2011; Il principio giurisprudenziale della bona fides nella compravendita inmobiliare, en "Presentazione degli Scritti scelti di Diritto Romano di C.A. Cannata»; Seminario Aristec "Dai giuristi ai Codici, dai Codici ai giuristi», Roma 20.21 de febrero del 2012 (en prensa). Sobre las reglas de las Partidas y medievales, vid. Reinoso-Barbero, El Derecho Romano como desideratum del Derecho del tercer millenium. Los principios Generales del Derecho, "Sistema jurídico latinoamericano y unificación del derecho», Roma-México, 2006, 239-318 (= en «Roma e America. Diritto Romano Comune», 3, 1997, 23-90). 
La antigua compilación española del siglo XIII equipara la regula a la ley con la parcial traducción de la definición de regula de Paulo, en D.50.1.17.7:

Regula est quae rem quae st breviter enarrat. Non ex regula ius sumatur sed ex iure quod est regula fiat...

"Regla es Ley dictada brevemente con palabras generales, que demuestra ayna la cosa sobre que fabla e ha fuerza de ley: fueras ende en aquellas cosas sobre que fablase alguna ley señalada de aqueste nuestro Libro que fuese contrario a ella. Ca entonces deve ser guardado lo que la ley manda e non lo que la regla dice.»

En las actuales sentencias de los Tribunales y Cortes de Justicia aparece innumerables veces citada la regla:

Bona fides ques in contractibus exigitur aequitatem summam desiderat (D.16.3.31 pr.) y las variantes a las que nos referiremos.

Trifonino, en este texto muy estudiado, ofrece varios ejemplos de depósitos en los que debe prevalecer la equidad. Se discute si un reo de pena capital, o un ladrón deposita una cantidad de dinero, en su propietario o en otra persona, a quien debe devolverse. Sobre lo que prescriben el derecho de gentes, civil o pretorio debe prevalecer la equidad y la justicia que da a cada uno lo suyo ${ }^{2}$. Responde que se ha de devolver al propietario y no al depositante porque me lo quitaron por acto muy criminal.

En los contratos de la legislación visigoda se realiza un abandono de los principios clásicos, al desaparecer las acciones y las reglas que justifican la concesión, y aparece una regresión hacia el furtum, conforme a las reglas de los juristas republicanos. En el Derecho hispano de la Recepción, las leyes de Partidas retornan a los principios clásicos y ofrecen como ejemplos las decisiones casuísticas de los juristas.

\section{LOS PRINCIPIOS SOBRE LOS CONTRATOS EN LA LEGISLACIÓN DE LOS VISIGODOS}

En el siglo pasado existió una viva y prolongada polémica entre romanistas y germanistas sobre el origen y caracteres de las leyes godas. El objeto de discusiones y críticas se centra en los principios

2 Vid CERAMI, Bona fides in contractibus (Trifoninus, 9 disp.), en Studi in honore di A. Palazzo, III, Turín, 2009, 139 ss. y bibliografia citada. 
de la territorialidad o de la personalidad de la legislación de los visigodos ${ }^{3}$.

El Derecho Romano del Bajo Imperio, por medio del Breviario de Alarico o Lex Romana Visighotorum, es el marco de la romanización y se discute su vigencia personal para los ciudadanos romanos o territorial para godos y romanos. El Código de Eurico se considera por Álvaro d'Ors como el «monumento del Derecho Romano Vulgar» y la posterior legislación de los monarcas visigodos, posteriores a Leovigildo, con el Liber iudiciorum como la introducción y adaptación a las costumbres germánicas y feudales.

Sobre la discutida compatibilidad del Breviario Alariciano y el Código de Eurico, Álvaro d'Ors afirma:

«El Breviario de Alarico no era una nueva ley en sentido estricto, de un nuevo Código que suplantara al de Eurico, sino de una gran obra de carácter general para la formación de los jueces y ayuda de los mismos en los casos no previstos por el Código Euriciano; es decir, el Breviario tuvo el mismo carácter didascálico que pocos años después iba a tener, en Oriente, el Digesto de Justiniano, y unos siglos después -a mediados del siglo XIII-, en Castilla, la Ley de Partidas, de Alfonso X el Sabio.»

\section{TITULUS XXVII DEL CÓDIGO DE EURICO: DE COMMENDATIS VEL COMMODATIS}

En la edición del Ceur d'Ors sostiene que en este título se tratan los contratos de depósito, mutuo y comodato. Commendatum es el término vulgar del depósito y en el se incluyen también el mutuo y los préstamos. Después se menciona el comodato. El mismo autor afirma que estos negocios que eran diferentes en las categorías ju-

3 Bibliografía histórica general: AGUADO BLEYE, Manual de Historia de España, Bilbao, 1927, 2; AMÉRICO CASTRO, España en su historia. Cristianos, moros y judios, Buenos Aires, 1948; La realidad histórica de España, Méjico,1954; ARTOLA, Historia de España, Madrid, 1973; GARCÍA DE CORTÁZAR, Sociedad y organización del espacio en la España Medieval, Granada, 2004; CLAVERÍA, Estudios hispanosuecos, Granada,1954, 93-100; LA FUENTE, Historia General de España, II; ORTEGA Y GASSET, La España invertebrada,; Sánchez Albornoz, En torno a los orígenes del feudalismo: Fideles y gardingos en la Monarquía visigoda, Mendoza 1942; TORRES LÓPEZ, El Estado visigótico, en AHDE, 3, 1926, 307 ss.; TARRADELL, La España antigua. Historia económica de España, Barcelona, 1959; VICENS VIVES, Historia social y económica de España y América, I, Barcelona, 1957. De especial importancia son los continuamente citados: A. D'ORS, Estudios Visigóticos I, en Cuadernos del Instituto Jurídico Español, 5, Roma-Madrid, 1956, El Código de Eurico, Estudios Visigóticos II, en Cuadernos del Instituto Jurídico Español, 12, Roma-Madrid, 1960. 
risprudenciales y en las diferencias procesales se presentan como análogos en los contratos postclásicos y bajo el criterio de la responsabilidad se unifican en la culpa contractual. Se observa en estos textos el general carácter delictual y el recurso al furtum como tema central.

Las leyes 278 y 279 (véanse textos) tratan del depósito o comodato del caballo o de otro género de animales. Se distingue el comodato concedido a cambio de precio del gratuito, cuando para los clásicos era siempre gratuito ya que si mediaba precio se convertía en arrendamiento (Labeón, D.13.6.5.12). La sanción por el incumplimiento era la entrega de un caballo del mismo valor, en caso de culpa del comodatario ${ }^{4}$.

La consideración generalizada del furtum representa un regreso del primitivismo de los juristas republicanos. En el famoso caso del caballo dado en comodato que se lleva más lejos de lo convenido ${ }^{5}$, Bruto respondía que era responsable de hurto el que llevaba el caballo a Ariccia o mas lejos de lo convenido. Quinto Mucio aplicaba la siguiente regla: "El que recibe una cosa en depósito y la usa, o recibe una cosa para usarla y la usa con un fin distinto del convenido, es responsable de hurto».

\section{TITULUS DE VENDITIONIBUS}

La ley 293 (vid. Fuentes) trata de la permuta que considera igual a la venta: Conmutatio tale qualem emptio habeat firmitatem ${ }^{6}$.

4 Tit. De commendatis vel commodatis. CCLXXVIII. Qui cavallum aut quodlibet animalium genus ad custodiendum mercede placita commendaverit, si perierit id, aliud eiusdem meriti ille qui commendata suscepit exsolvat; si turnen mercedem fuerit pro custudia consecutus. 2. Quod si etiam / qui nulla placita mercede susceperat ea mortua esse probaverit, nec ille mercedem requirat, nec ab illo aliquid requiratur; ea lamen ratione ut praebeat sacramentum qui commendata susceperat quod non per suam culpan nec per negligentiam morte consumpta sint. 3. Eadem et de commodatis forma servetur.

CCLXXVIIII. Si quis alicui iumentum praestiterit, et illud per aliquam infirmitatem aput eum moritur, sacramentum primitus praebere deber quod non per suam culpam morte consumptum sit, et nihil cogatur exsolvere. 2. Sin autem nimium sedeudo vel fasces carricando mortuum fuerit, eiusdem meriti caballum reddat. 3. Si vero idem praestitus alicui aliquid debilitatis intulerit vel damni, ille conponat qui eum aput se suscepturn habuisse dinoscitur.

5 Valerio Máximo 8.2.4; Aulo Gelio, Nott Att.6.1. Sabino y Paulo, D.47.2.40. Vid. GARCÍA GARRIDO, Casuismo y Jurisprudencia romana (Responsa), Madrid 2004, 229 ss.

6 Según A. D’ORS, cit., 211, «Se trata de una antigua manera de ver superada por los Proculeyanos y que se restablece victoriosa en el derecho vulgar». 
Según Levy y A. d'Ors la compraventa en el Ceur acoge el régimen del Derecho Romano Vulgar. Niegan que existan influencias de la tradición germánica.

El negocio de la venta tiene por objeto la adquisición de la propiedad, según la reconstrucción de las leyes euricianas, pero se encuentran huellas de la regulación de la compraventa consensual en relación con la traditio o entrega de la cosa y también del pago del precio. La equiparación con la permuta no implica que la venta sea considerada como un negocio real (A. d'Ors). La entrega de la cosa se considera cumplimiento del contrato como era en la tradición romanística. El vendedor debe presentar un fideiussor o actor secundus (Ceur 295). El precio debía entregarse con presencia de testigos pero también se admitía con una declaración en el documento de venta (per scripturam o pretium datum) ${ }^{7}$.

Existían reglas especiales sobre la compraventa de res aliena o a non domino:

Ley 289: Quoties de vindita re contentio conmovetur, si alienam fuisse constiterit comparetur. 2. Et domino qui vendere aliena praesumserit duplum cogatur exsolveret, nihilominus emptori quod accepit pretium redditurus; 3. Et quidquid ad comparate rei profectum studio suae utilitatis emptor adiecerit a locorum iudicibus estimetur, et ei qui laborasset cognoscitur a venditore iuis alieni satisfactio iusta reddatur.

Para A. d'Ors la venta de la res aliena está incluida en las compraventas prohibidas. Se establece que no debe ocasionarle ningún perjuicio al dueño (Nullum domino praeiudicium comparetur), con la con la restitución del precio que le corresponde (Et domino qui vendere aliena praesumserit duplum cogatur exsolvere); el vendedor debe restituir el precio al comprador (pretium redditurus) y también pagar los gastos (suae utilitatis emptor adiecerit).

El comprador que con mala fe contrata sabiendo que la cosa no pertenece al vendedor comete furtum (LV. Ant 7,2,7-9); (in numero furantium habeatur; si quis rem furtivam sciens a fure comparavit tamquam fur componere non moretur). En este caso debe restituir el duplum. Si el comprador es de buena fe se le concede un tiempo para buscar al vendedor ladrón y si no lo encuentra debe jurar y pre-

7 Tit. De Venditionibus. CCLXXXVI. Venditio per scripturam facta plenam habeat. firmitatem. 2. Si etiam scriptura facta non fuerit, datum praetium testibus conprobatur, et emptio habeat firmitatem. 3. Venditio si fuerit violenter extorta, id est per metum mortis aut per custodiam, nulla valeat ratione. 
sentar testigos o un auctor, o fideiussor. La restitutio es ex medietate del precio recibido.

\section{LAS PARTIDAS}

A) Las Partidas de Alfonso X el Sabio regresan al carácter clásico del comodato. En la Partida V 5. Prf- y 1 encontramos la definición y la distinción entre mutuo o préstamo y comodato:

"... e son dos maneras de emprestamo: e la otra manera es es de cualquier de las otras cosas... asi como cavallo, u otra bestia, o libro o otras cosas semejantes. E tal prestamo como este dicien en latin Commodatum que quier tanto dezir como cosa que presta un ome a otro para vsar o aprovecharse della, mas non para ganar el señorio de la cosa prestada...E esto lo faze por gracia o por amor no tomando aquel que lo ha porende precio de loguero, nin de otra cosa ninguna.»

Las Partidas presentan los casos romanos como ejemplos por medio de la generalización de los supuestos. La exposición procesal y la concesión de las acciones se sustituye por las reglas jurídicas y la posición de las partes: El caso del caballo dado en comodato se cita 5 veces en las leyes del título: el comodatario responde en el caso «dell cavallo o la bestia prestada para una jornada alla o la llevase mas lueñe o se muriese o se perdiese».

B) La compraventa de res aliena et a non domino ${ }^{8}$.

La compilación de Alfonso X con la divulgación del Derecho Justinianeo y las notas de los glosadores, regresa al régimen clásico de

8 Los textos jurisprudenciales sobre la venta de cosa ajena son muy numerosos y se encuentran en varios títulos del Digesto:

D.21,3,2 Pomponius libro secundo ex Plautio. Si a Titio fundum emeris qui Sempronii erat isque tibi traditus fuerit, pretio autem soluto Titius Sempronio heres exstiterit et eundem fundum Maevio vendiderit et tradiderit: Iulianus ait aequius esse priorem te tueri, quia et si ipse Titius fundum a te peteret, exceptione summoveretur et si ipse Titius eum possideret, Publiciana peteres.

Iulianus ait: aequius esse priorem emptorem tueri.

Id: aequius est ut tu potior sit.

Id: si quidem a non domino emerint, potior sit cui priori res tradita est, quod si a diversis non dominis, melior causa sit possidentis quam petendis.

Neratius: Uterque nostrum eadem rem emit a non domino, cum emptio venditioque sine dolo malo fiere ... id est nobis tuendum est ... Qui prior eius ius adprenhendit, hoc est, cui primum tradita esto. 
la compraventa consensual, que continúa vigente en el Código Civil español y en los Códigos de la América hispana.

La Partida V, título V, ley XIX trata de la compraventa a non domino con la distinción entre el comprador que conocía que la cosa era ajena del que lo ignoraba9 ${ }^{9}$. La ley L del mismo título trata del hombre que vende dos veces la misma cosa en tiempos sucesivos. Concede la tenencia de la cosa a quien primero recibió la posesión. Reproduce la casuística clásica sobre los distintos supuestos de la entrega de la cosa y del pago del precio de los dos compradores ${ }^{10}$. La ley siguiente LI traduce la casuística del texto de Juliano y de los otros juristas clásicos con los supuestos de que también la segunda venta realizada por el que ya era propietario también era ajena por haberla vendido antes al primer comprador ${ }^{11}$.

Ulpianus: ac per hoc intellegeretur eum fundum rursus vendisse, quem in bonis non habere.

Modestinus: Bonae fidei emptor esse videtur qui ignoravit eam rem alienam esse, aut putavit eum qui vendidit ius vendendi habere, ut puta procuratores aut tutorem esse.

Vid. GARCÍA GARRIDO, El fundo que se vendió dos veces, en Casuismo y jurisprudencia, cit., 299 ss.

${ }^{9}$ Como se puede vender la cosa agena. Cosa agena vendiendo un ome a otro, valdra la vendida. Pero aquel que tal compra faze, o sabe que aquella cosa, que assi compra, que non es de aquel que gela vende, o creya que es suya. E si sabe que es agena, maguer que la torne despues por juyzio a aquel cuya es, non es tenudo el vendedor de tornarle el precio; fueras, si quando gela vendio, se obligo que lo tornasse, si aquel cuya era aquella cosa la demandasse, e la cobrasse. Mas si non supiese el comprador que era la cosa agena quando la compro, estonce non seria el vendedor tenudo tan solamente de pechar el precio, mas todos los daños, e los menoscabos, que le viniessen por razon de aquella vendida que le fizo.

${ }_{10}$ Del ome que vende la cosa dos vegadas a dos omes en tiempos departidos, qual dellos la deue auer. Vna cosa vendiendo vn ome dos vezes a dos omes en tiempos departidos, si aquel a quien la vendio primeramente, passa a la tenencia de la cosa e paga el precio, esse la deue auer, e non el otro. Pero tenudo es el vendedor, de tornar el precio a aquel que la vendio a postremas, si lo auie recebido, con todos los daños, e los menoscabos, que le vinieron por razon de tal vendida, porque la fizo engañosamente. Otrosi dezimos, que si el postrimero comprador passasse a la tenencia, e a la possession, e pagasse el precio, que ella deue auer, e non el primero. E es otrosi el vendedor tenudo de tornar el precio, si lo auia recebido, con los daños, e los menoscabos, que vinieron por esta razon al primer comprador. Otrosi dezimos; si alguno vendieisse a dos omes cosa agena en tiempos departidos, si acaesciere que ayan pleyto entre si ambos los compradores sobre aquella cosa, qualquier dellos que quiere primeramente la posseasion, aquel ha mayor derecho en ella: e a aquel deue fincar, maguer non ouiesse pagado el precio. Pero quando quier que el señor de la cosa venga a demandarla, saluo finca su derecho en ella.

11 Del ome que vende la cosa agena a dos omes dos vezes, qual dellos la deue auer. Agena cosa vendiendo vn ome a otro, e dandole luego la possession della; si despues que la ouiesse assi vendida, ganasse el vendedor el señorio de aquella cosa, como si le establesciesse por su heredero aquel cuya era, o gela diesse de otra guisa; si por razon que ouiesse ya ganado el señorio de la cosa, la vendiesse despues a otro, e el postrimero comprador mouiesse pleyto sobre ella al primero, dezimos, que este primero ha 


\section{LOS CÓDIGOS}

A) Códigos americanos que reciben la tradición romanística de las Partidas

Código Civil de Chile: art. 1817: Si alguien vende separadamente una misma cosa a dos personas, el comprador que haya entrado en posesión será preferido al otro; si ha hecho entrega a los dos, aquel a quien se haya hecho primero será preferido.

Art. 1819: Vendida y entregada a otro una cosa ajena, si el vendedor adquiere después el dominio, se mirará al comprador como verdadero dueño desde la fecha de la tradición. Por consiguiente si el vendedor lo vendiese a otra persona después de adquirido el dominio, subsistirá el dominio de ella en el primer comprador.

Código Civil argentino art. 1329: Las cosas ajenas no pueden venderse... el vendedor después de entregada la cosa no puede demandar la nulidad de la venta ni la restitución de la cosa. El legislador cita Fuero Real. 3.2.6: si el comprador sabe que la cosa era ajena debe pagar el doble.

\section{B) Códigos actuales}

Art. 1.473 CC: Si una misma cosa se hubiese vendido a diferentes compradores, la propiedad se trasferirá a la persona que primero haya tomado posesión de ella de buena fe si fuere mueble. Si fuere inmueble, la propiedad pertenecerá al adquirente que antes la haya inscrito en el Registro. Cuando no haya inscripción pertenecerá la propiedad a quien de buena fe sea primero en la posesión y, faltando éste, a quien presente título de fecha más antigua, siempre que haya buena fe.

Art. 34 de la Ley hipotecaria de 1946: El tercero que de buena fe adquiera a título oneroso algún derecho de persona que en el Registro aparezca con facultades para trasmitirlo será mantenido en su adqui-

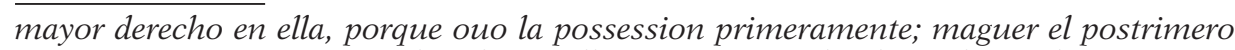
razonasse, que auia mayor derecho en ella, porque quando al otro la vendio, non auia el seiñorio el vendedor, e auialo ya ganado, quando la vendio a el. Mas si alguo ome vendiesse a otro alguna cosa que non fuesse suya, e aquella cosa misma vendiesse el señor de ella a otro despues; este postrimero comprador que la compro del que ha mayor derecho en ella, este la deue auer. Fueras ende, si el que la vendio primeramente, auia razon derecha para venderla; como si la touiesse en peños, e quando le fue empeñada, la recibio a tal pleyto, que la pudiesse vender si gela non quitassen a dia señalado; o si fuesse personero, e en la personeria le fuesse otorgado poder de la vender, e la vendiesse en ante que sopiesse, que el señor de la cosa la queria vender a otro. 
sición una vez que haya inscrito su derecho aunque después se anule o se resuelva el del otorgante por virtud de causas que no constan en el Registro. La buena fe del tercero se presume siempre mientras no se pruebe que conocía la inexactitud del Registro.

Art. 1.462 CC. Se entenderá entregada la cosa vendida cuando se ponga en poder y posesión del comprador. Cuando se haga la venta mediante escritura pública, el otorgamiento de ésta equivaldrá a la entrega de la cosa objeto del contrato si de la misma escritura no resultare o se dedujere claramente lo contrario.

Art. 1.599 del Code français: La vente de la chose d'autri es nulle.

Art. 1.478 del Codice italiano: Se al momento del contratto la cosa venduta non era proprietà del venditore, questo è obbligato a procurarne l'acquisto al compratore.

$\S 435$ del BGB: Die Sache ist frei von Rechtsmängeln, wenn Dritte in Bezug auf die Sache keine oder nur die im Kaufvertrag übernommenen Rechte gegen den Käufer geltend machen können. Einem Rechtsmangel steht es gleich, wenn im Grundbuch ein Recht eingetragen ist, das nicht besteht.

Los principios del derecho europeo de los contratos (Lando): El contrato no es inválido por el simple hecho que en el momento de su conclusión la prestación de la obligación que se deriva del contrato fuese imposible o que una de las partes no estuviese legitimada para disponer de los derechos a los que el contrato se refiere.

\section{LA JURISPRUDENCIA}

Los principios citados:

El principio: Bona fides qui in contractibus exigitur aequitatem summam desiderat. Trifonino, D.16.3.31.

Variantes: Bona fides exigit quod convenit fiat. Javoleno, D.19.2.21.

Bona fides praesumitur si titulus verus. Bartolo, Alciato, Dino.

Bonae fidei emptor esse videtur qui ignoravit rem alienam esse. Modestino, D.50.16.109.

Sentencias del Tribunal Supremo español ${ }^{12}$ :

Hechos: D. Arsenio vende en contrato privado diversos inmuebles a la Sociedad Dolsa en 2001. En el año siguiente 2002 vende los

12 STS 720/2011. Fondo Documental. Cendoj. Consejo General del Poder Judicial. 
mismos inmuebles a M. ${ }^{a}$ Rosa en documento notarial inscrito en el Registro de la Propiedad. La S. Dolsa acciona contra el vendedor y la segunda compradora solicitando la nulidad de la escritura pública y de la inscripción registral. En la reconvención, los demandados vendedor y $2{ }^{\text {a }}$ compradora solicitan la nulidad del contrato privado de venta con la S. Dolsa. El Juzgado de 1. ${ }^{a}$ instancia de Mula en 2005 declara la nulidad del primer contrato en aplicación de art. 1.473 del CC sobre la prioridad de la inscripción registral del vendedor y la 2. ${ }^{a}$ compradora. Dolsa apela ante la Audiencia Provincial de Murcia, que declara la validez del primer contrato con Dolsa y la consiguiente nulidad de la venta e inscripción posterior con fundamento en la falta de buena fe demostrada por el conocimiento del vendedor del primer contrato con Dolsa. El vendedor D. Arsenio apela en casación ante el Tribunal Supremo. La Sentencia de este Tribunal confirma la sentencia de la Audiencia declarando la validez del primer contrato con Dolsa.

En los fundamentos jurídicos el TS considera que en este caso de doble venta ninguno de los litigantes ha tenido la posesión de los inmuebles, rechazando la alegación de la possessio ficta del art. 1.462 CC. Sobre la ausencia de la buena fe cita la sentencia anterior de 22.12.200 que afirma:

«La buena fe en materia de propiedad y derechos reales consiste en su aspecto positivo en la creencia por parte de quien pretende ampararse en la protección registral de que la persona que adquirió la finca de que se trate era dueño de ella y podía transmitirle su dominio, y en sentido negativo, en la ignorancia y desconocimiento de inexactitudes o vicios invalidatorios que puedan afectar a la titularidad del enajenante por lo que carecen de tal cualidad quienes tienen noticias perfectas de la situación extra tabular o de las posibles causas capaces de enervar el título de su transferente.»

En una sentencia más reciente de 13 de mayo de 2013, con la intervención del mismo ponente Prof. O’Callagan, el TS confirma los argumentos anteriores sobre la buena fe exigible en los derechos reales que no se refiere a un estado de conducta sino de conocimiento ${ }^{13}$.

13 Sentencia Ts 13.05.2013: Hechos: D. Carlos J. compra en documento privado una finca que vende D. Tomas y toma posesión material de la misma desde la fecha del contrato hasta el 2000. Ante la negativa del vendedor de otorgar escritura pública, $D$. Carlos acciona y el Juzgado obliga al vendedor a otorgarla. D. Tomás, titular registral vende en el tiempo intermedio la misma finca a D. Apolonio, y posteriormente se vende a varias sociedades con escrituras públicas e inscripción en el Registro de la Propiedad. Así se llega al último comprador la Sociedad demandante Bcn, conocedora de la situación del primer poseedor D. Carlos J. y de los procesos civiles y penales de reclamación de la finca. Las sentencias de instancia califican la conducta de las personas físicas y jurídicas que intervienen constitutivas de mala fe. El TS rechaza los motivos alegados y 
La misma justificación de considerar la primera venta válida en aplicación del principio de la buena fe es la que argumentan los juristas clásicos y se mantiene en la tradición romanística.

confirma la sentencia apelada por la última sociedad compradora. En cuanto al motivo de la pretendida infracción del art. 1.473 se desestima porque el presenta caso no es una doble venta y no se aplica ese artículo porque cuando tomas vendió en escritura pública la finca ya no era de su propiedad, a pesar de que siguiera siendo titular registral, ya que no era dueño pues había vendido la finca a Carlos en documento privado (título) y éste había tomado posesión material de la finca (modo). 